\title{
IKLIM ORGANISASI, KEPUASAN KERJA DAN LOYALITAS KERJA BERPENGARUH TERHADAP ORGANIZATIONAL CITIZENSHIP BEHAVIOR (OCB)
}

\author{
Kadek Nabella Sri Astarini ${ }^{1}$ \\ I Wayan Mudiartha Utama ${ }^{2}$ \\ ${ }^{1,2}$ Fakultas Ekonomi dan Bisnis Universitas Udayana (Unud), Bali, Indonesia \\ email: nabellasar067@gmail.com
}

\begin{abstract}
ABSTRAK
Organizational citizenship behaviour adalah elemen penting dalam suatu organisasi. Apabila karyawan merasa tidak puas dengan pekerjaan, situasi kerja, rekan kerja dan atasan di perusahaannya maka akan dapat mengakibatkan semakin tingginya turnover intention di perusahaan tersebut. Penelitian ini bertujuan untuk menjelaskan pengaruh iklim organisasi, kepuasan kerja, dan loyalitas kerja terhadap organizational citizenship behaviour pada Jimbaran Bay Seafood Café (JBS) Kedonganan. Responden pada penelitian ini adalah seluruh karyawan yang berjumlah 58 orang. Teknik pengambilan sampel menggunakan sampling jenuh. Metode pengumpulan data dilakukan dengan metode wawancara terbuka dan kuesioner. Teknik analisis yang digunakan adalah regresi linier berganda. Hasil analisis menunjukkan bahwa iklim organisasi, kepuasan kerja dan Loyalitas kerja berpengaruh positif dan signifikan terhadap organizational citizenship behaviour. Hasil penelitian ini mengungkapkan pentingnya pihak manajemen dalam memperhatikan seberapa besar iklim organisasi, kepuasan kerja, dan loyalitas kerja dalam mempengaruhi tingkat organizational citizenship behaviour (OCB)

Kata kunci : iklim organisasi, kepuasan kerja, loyalitas kerja, organizational citizenship behavior
\end{abstract}

\begin{abstract}
Organizational citizenship behavior is an important element in an organization. If employees feel dissatisfied with work situations, it will lead to higher turnover intentions in the company. This study aims to explain the influence of organizational climate, job satisfaction, and work loyalty on organizational citizenship behavior in Jimbaran Bay Seafood Café (JBS) Kedonganan. The respondents in this study were all 58 employees. The sampling technique uses saturated sampling. The method of data collection is done by the method of open interview and questionnaire. The analysis technique used is multiple linear regression. The results of the analysis show that organizational climate, job satisfaction and work loyalty have a positive and significant effect on organizational citizenship behavior. The results of this study reveal the importance of management in considering how much organizational climate, job satisfaction, and work loyalty in influencing the level of organizational citizenship behavior $(O C B)$

Keywords : organizational climate, job satisfaction, job loyalty, organizational citizenship behavior
\end{abstract}




\section{PENDAHULUAN}

Bali merupakan pulau yang memiliki banyak objek wisata yang sangat dikagumi oleh para wisatawan lokal dan wisatawan mancanegara. Salah satu objek wisata yang sangat dikagumi oleh para wisatawan adalah pantai. Pantai memiliki pemandangan yang indah sehingga mampu menarik perhatian. Selain pemandangan yang dimiliki, wisatawan tentu sangat tertarik dengan kuliner seafood yang menjadi ciri khas jika sedang berkunjung ke Bali. Semakin banyaknya peluang di dunia kuliner terutama dalam olahan ikan laut menyebabkan banyak terdapat café/restaurant seafood yang berada di pinggir pantai. Usaha yang sukses tentu membutuhkan strategi yang tepat dalam mengetahui kelemahan, kelebihan, peluang serta ancaman di dalam perusahaan (Prameswari \& Suwandana, 2017).

Penggunaan strategi yang baik, tentu harus diimbangi dengan cara perusahaan dalam memelihara dan mengelola sumber daya manusianya agar dapat meningkatkan efektifitas dan efisiensi organisasi dalam bekerja (Prameswari \& Suwandana, 2017). Manajer dan pemimpin serta bagian yang menangani SDM harus dapat mengerti masalah manajemen SDM pula (Sharma, 2016). Jika SDM perusahaan mempunyai kinerja yang baik maka berdampak langsung pada kemajuan perusahaan serta dapat mencapai tujuan yang direncanakan (Mahardika \& Wibawa, 2019).

Sikap yang ditunjukkan oleh karyawan dalam bekerja akan sangat mempengaruhi kinerja karyawan. Apabila karyawan merasa tidak puas dengan pekerjaan, situasi kerja, rekan kerja dan atasan di perusahaannya maka akan dapat mengakibatkan semakin tingginya turnover intention di perusahaan tersebut (Puangyoykeaw \& Nishide, 2015). Agar dapat mengurangi turnover intention di perusahaan, tentu dibutuhkan karyawan yang memiliki sifat yang mampu melakukan tugasnya dengan lebih dari sekedar tugas formalnya, sehingga dapat memberikan kinerja yang sesuai harapan perusahaan yang lebih dikenal dengan Organizational Citizenship Behavior (OCB) (Fitriani \& Dewi, 2017)

Ukkas \& Latif (2017) mendefinisikan Organizational Citizenship Behavior (OCB) adalah seorang karyawan yang melakukan pekerjaan di luar dari job descriptionnya secara sukarela tanpa adanya paksaan oleh pihak manapun, selain itu, karyawan juga memiliki perasaan puas jika dapat membantu dan mengerjakan sesuatu yang lebih, sehingga dapat membantu meningkatkan efektivitas organisasi. Harper (2015) perilaku yang dapat meningkatkan produktivitas karyawan di dalam perusahaan salah satunya yaitu perilaku extra-role atau disebut perilaku OCB. Nurhayati et al. (2016) menyatakan bahwa Organizational Citizenship Behavior (OCB) merupakan aspek yang unik dari aktivitas individual dalam bekerja.

Perilaku OCB karyawan dapat dipengaruhi oleh beberapa faktor yaitu budaya organisasi, iklim organisasi, karakteristik individu (persepsi keadilan, kepuasan kerja, komitmen organisasional, persepsi terhadap dukungan organisasi, dan loyalitas kerja), kepribadian dan suasana hati (mood), kualitas interaksi (Rauf, 2014). Perusahaan harus mengutamakan iklim organisasi yang kondusif, apabila iklim organisasi di perusahaan baik maka hal tersebut dapat menumbuhkan semangat kerja karyawan sekaligus akan berdampak pada OCB karyawan (Khan et $a l .$, 2015). Iklim dalam perusahaan akan menentukan bagaimana cara karyawan 
melaksanakan tugas dan tanggung jawab sesuai dengan prosedur (Nurhayati et al., 2016).

Iklim organisasi juga dapat mendorong kenyaman bagi anggota organisasi dalam melakukan pekerjaan sehingga akan mampu menghasilkan kinerja yang tinggi. Karyawan merasakan perusahaan memperhatikan dan peduli terhadap dirinya dapat menyebabkan mereka melakukan perilaku-perilaku di luar tanggung jawab kerja di dalam perusahaan, sehingga jika perusahaan mampu memberikan iklim yang dipersepsikan secara positif oleh karyawan maka akan memunculkan perilaku Organizational Citizenship Behavior (OCB) (Masoud et al., 2014)

Penelitian sebelumnya mengenai iklim organisasi terhadap organizational Citizenship Behavior (OCB) penelitian Subramani et al. (2015), Pozveh \& Karimi (2017) dan Sukarman et al. (2018) menunjukkan bahwa iklim organisasi dan motivasi kerja berpengaruh signifikan terhadap OCB. Artinya semakin kondusif iklim organisasi yang dipersepsikan oleh karyawan maka semakin baik pula OCB karyawan. Hubungan ini dapat dijelaskan bahwa dalam melaksanakan tugas yang melebihi dari kewajiban formal dapat ditentukan apabila karyawan mempersepsi positif iklim organisasi yang ada. Gunduz (2014) dan Berberoglu (2018) menyatakan bahwa terdapat pengaruh yang signifikan iklim organisasi terhadap OCB.

Kepuasan kerja dan iklim organisasi adalah elemen penting dalam organisasi. Karyawan yang puas akan menunjukkan sikap yang positif bagi organisasi, membantu rekan kerjanya secara iklas karena mereka merasa ingin membalas pengalaman positifnya. Sunarta (2019) menyatakan bahwa kepuasan kerja mewakili perasaan negatif dan positif dari persepsi karyawan terhadap pekerjaan yang dihadapinya, yaitu perasaan dalam berprestasi dan meraih kesuksesan di dalam pekerjaan, Apabila seorang karyawan merasakan puas terhadap pekerjaannya, tentu ia akan berupaya secara maksimal dalam menyelesaikan tugas dan tanggung jawabnya.

Karyawan yang puas akan lebih mungkin berbicara positif tentang organisasi, membantu orang lain, dan jauh melebihi harapan yang normal dalam pekerjaan (Lubis, 2015). Apabila seseorang merasa mendapatkan kepuasan dari pekerjaan yang dilakukannya selama ini, maka itu cukup menjadi motivasinya untuk tetap tinggal dan bertahan akan segala kondisi yang diterima. Kepuasan kerja tidak terlihat hanya pada saat melaksanakan pekerjaanya saja, namun kepuasan kerja dapat berkaitan dengan aspek lain seperti interaksi dengan atasan, rekan kerja, serta terlihat nyaman dengan lingkungan kerja (Yanti \& Supartha, 2017).

Hasil penelitian lainnya menunjukkan bahwa kepuasan kerja mampu mempengaruhi organizational citizenship behaviour, hal ini ditunjukkan dari penelitian Pitaloka \& Sofia (2015) menyatakan jika karyawan puas dengan pekerjaan mereka, mereka akan mendukung tujuan, sasaran, dan akan mempertahakan diri dalam perusahaan.Kepuasan kerja yang baik akan membuat karyawan merasa terlibat dan bertanggung jawab di dalam melakukan pekerjaanya, sehingga kepuasan kerja berpengaruh positif terhadap OCB (Devi \& Adnyani, 2015). Putrana et al. (2016) menyatakan kepuasan kerja akan mendorong karyawan untuk memperlihatkan perilaku organizational citizenship behavio (OCB), disebabkan karena karyawan akan mendapat kepuasan dalam pekerjaannya, 
sehingga mereka akan cenderung memaknai pekerjaanya dengan penuh tanggung jawab.

Karyawan melakukan OCB disebabkan oleh tingginya kepuasan kerja dan loyalitas karyawan terhadap perusahaan, sehingga karyawan akan mampu memberikan hasil kerja yang lebih kepada perusahaan (Nurhayati et al., 2016). Rusdi \& Chan (2015), menunjukkan bahwa loyalitas karyawan berpengaruh positif dan signifikan terhadap OCB. Bila karyawan memiliki loyalitas tinggi, maka karyawan memiliki pengabdian yang tinggi terhadap pekerjaan dan mempunyai keinginan untuk melebihi standar pencapaian dalam setiap aspek. Aspek utama yang akan mendorong karyawan untuk berkontribusi lebih dari standar kepada perusahaan adalah loyalitas dalam bekerja.

Dalam memaksimalkan potensi karyawan dalam suatu perusahaan, karyawan haruslah memiliki loyalitas kerja yang tinggi karena, jika karyawan sudah loyal terhadap perusahaan, maka karyawan tersebut akan sukarela bekerja pada perusahaannya (Yu et al., 2015). Hal yang menyebabkan kurangnya loyalitas karyawan adalah kurang perhatian pimpinan terhadap bawahan, pembayaran pekerjaan itu sendiri, promosi yang akan didapatkan, atasan ditempat kerja dan juga rekan-rekan sesama karyawan yang dapat menciptakan kenyamanan tinggi bagi karyawan tentu yang dapat berpengaruh terhadap keseriusan karyawan dalam bekerja (Zayas-ortiz et al., 2015).

Penelitian ini dilaksanakan di Jimbaran Bay Seafood (JBS) Café Kedonganan. Jimbaran Bay Seafood (JBS) Café Kedonganan merupakan salah satu restoran yang menyajikan menu makanan olahan laut yang terletak di pinggir pantai kedonganan. Restoran yang bertepat di jalan pantai kedonganan, kuta ,badung bali ini sangat ramai dikunjungi para konsumen saat makan malam. Peran karyawan di Jimbaran Bay Seafood Café (JBS) harus diperhatikan kualitas kerjanya. Untuk dapat meningkatkan pelayanan di JBS Café tentu dibutuhkan karyawan yang mencerminkan sifat OCB. OCB memiliki peranan untuk dapat mengurangi kelemahan karyawan yang tidak mau bekerjasama antar karyawan dalam menyelesaikan pekerjaannya. Seperti contoh karyawan yang sedang tidak menangani (Handle) konsumen dapat membantu karyawan lain yang sedang kesusahan dalam menangani (Handle) konsumen yang banyak.

Setelah melakukan observasi dan wawancara pada karyawan JBS Cafe adapun permasalahan yang sering dihadapi terkait OCB adalah 6 karyawan menyatakan bahwa karyawan sering mengeluh jika menambah waktu kerja untuk menyelesaikan pekerjaan, hal ini disebabkan karena karyawan merasa beban kerja yang dirasakan karyawan cukup besar. Untuk mengatasi permasalahan tersebut, dapat dilihat bahwa karyawan dihadapkan pada sejumlah tugas dan tanggung jawab yang besar dan disisi lain kurangnya sifat karyawan dalam membantu sesama rekan kerjanya secara sukarela, maka dari itu sangat dibutuhkan perilaku extra role dari karyawan yang dapat dikenal dengan organizational citizenship behaviour. Peran iklim organisasi, kepuasan kerja, dan loyalitas kerja menjadi salah satu pertimbangan untuk dapat meningkatkan efektivitas dan efisiensi karyawan dalam jangka waktu lama melalui iklim organisasi yang tinggi, kepuasan kerja dari karyawan serta sikap loyal yang dimiliki oleh karyawan. 
Tujuan dari penelitian ini adalah untuk menjelaskan pengaruh iklim organisasi terhadap Organizational Citizenship Behavior (OCB), untuk menjelaskan pengaruh kepuasan kerja terhadap Organizational Citizenship Behavior (OCB) dan untuk menjelasan pengaruh loyalitas kerja terhadap Organizational Citizenship Behavior (OCB).

Teori yang digunakan dalam penelitian ini adalah teori pertukaran sosial (social exchange theory). Teori ini didasarkan pada hubungan yang semakin erat sampai pada saling percaya, loyal, dan saling berkomitmen antara kedua belah pihak. Teori pertukaran sosial menyatakan bahwa dalam sebuah hubungan sosial terdapat unsur timbal balik, reward atau ganjaran dan juga keuntungan yang saling mempengaruhi (Campbell, 2015).

Selain itu, teori ini juga menganalisis hubungan individu dengan orang lain dalam sebuah aktivitas yang akan menghasilkan hubungan timbal balik. Hubungan antara karyawan dengan perusahaan termasuk dalam pengaplikasian teori pertukaran sosial. Karyawan yang percaya bahwa perusahaan telah memberikan hal-hal positif kepadanya akan merasa harus membalas perbuatan tersebut. Teori ini bisa digunakan untuk meneliti fenomena hubungan sosial seseorang atau kelompok yang pindah atau berganti teman atau afiliasi kelompok, tinggal di kelompok kemudian keluar dan masuk. Dengan menggunakan konsep-konsep dasar terebut sebagai variabel independen dan tindakan pindah atau berganti sebagai variabel dependen (Mighfar, 2015)

Beberapa penelitian telah membuktikan bahwa iklim organisasi mempengaruhi OCB karyawan. Ningtias \& Sunuharyo (2018) menyatakan iklim organisasi memiliki pengaruh positif terhadap organizational citizenship behavior. Hasil penelitian lain juga sesuai dengan penelitian Lubis (2015), menunjukkan iklim organisasi memiliki pengaruh positif dan signifikan terhadap organizational citizenship behavior. Fanis \& Rahmi (2016) menyatakan iklim organisasi mempunyai pengaruh yang signifikan terhadap OCB. Hasil penelitian Shahin et al. (2015) menegaskan iklim organisasi menunjukkan gaya hidup orang dari sebuah organisasi, dengan menciptakan iklim organisasi yang kondusif akan menghasilkan organizational citizenship behavior.

Suifan (2016) menyatakan bahwa terdapat hubungan yang sangat signifikan antara iklim organisasi dan organizational citizenship behavior dengan arah positif bahwa semakin tinggi atau baik iklim organisasi akan meningkatkan organizational citizenship behavior. Ukkas \& Latif (2017) menyebutkan terdapat pengaruh positif dan signifikan iklim organisasi terhadap Organizational citizenship behaviour (OCB). Iklim organisasi berpengaruh positif dan signifikan terhadap organizational citizenship behavior oleh Mahendra \& Surya (2017). Berdasarkan uraian tersebut, maka dapat dirumuskan hipotesis sebagai berikut :

$\mathrm{H}_{1}$ : Iklim organisasi berpengaruh positif dan signifikan terhadap organizational citizenship behavior $(O C B)$.

Soegandhi et al. (2013) menyatakan bahwa kepuasan kerja berpengaruh positif dan signifikan terhadap organizational Citizenship Behavior karyawan PT. Surya Timur Sakti Jatim. Kepuasan kerja berpengaruh positif dan signifikan terhadap Organizational Citizenship Behavior (OCB). Semakin tinggi kepuasan kerja karyawan maka akan semakin meningkat Organizational Citizenship 
Behavior (OCB) (Nurhayati et al., 2016). Laksana \& Surya (2018) menyatakan bahwa kepuasan secara positif dan signifikan berpengaruh terhadap Organizational Citizenship Behavior (OCB). Hal ini menunjukkan semakin tinggi kepuasan kerja yang dimiliki oleh guru maka semakin tinggi pula tingkat OCB yang dimiliki guru SMAN 1 Blahbatuh. Wahyuni \& Supartha (2019), keadilan organisasional, komitmen organisasional dan kepuasan kerja berpengaruh positif dan signifikan terhadap Organizational Citizenship Behavior (OCB). Mahardika \& Wibawa (2019) menyatakan bahwa kepuasan kerja berpengaruh positif dan signifikan terhadap organizational citizenship behavior terhadap karyawan Focus Design Artglass Ubud. Berdasarkan uraian tersebut, dapat dirumuskan hipotesis sebagai berikut.

$\mathrm{H}_{2}$ : Kepuasan Kerja berpengaruh positif dan signifikan terhadap organizational citizenship behavior (OCB).

Prameswari \& Suwandana (2017) menyatakan perilaku organisasi menciptakan suatu iklim yang menunjang dalam loyalitas karyawan contohnya yaitu lamanya bekerja karyawan ditunjukkan dengan rendahnya tingkat turnover. Loyalitas kerja berpengaruh positif terhadap Organizational Citizenship Behavior karyawan PT. Surya Timur Sakti Jatim oleh Soegandhi et al. (2013). Rusdi \& Chan (2015), kepuasan kerja dan loyalitas kerja berpengaruh terhadap organizational citizenship behavior (OCB). Penelitian Nurhayati et al. (2016) menyebutkan loyalitas kerja berpengaruh positif dan signifikan terhadap Organizational Citizenship Behavior (OCB), artinya semakin tinggi loyalitas kerja karyawan maka akan semakin meningkat organizational citizenship behavior (OCB). Berdasarkan uraian tersebut, maka dapat dikemukakan hipotesis penelitian sebagai berikut.

$\mathrm{H}_{3}$ : Loyalitas kerja berpengaruh positif dan signifikan terhadap organizational citizenship behavior (OCB).

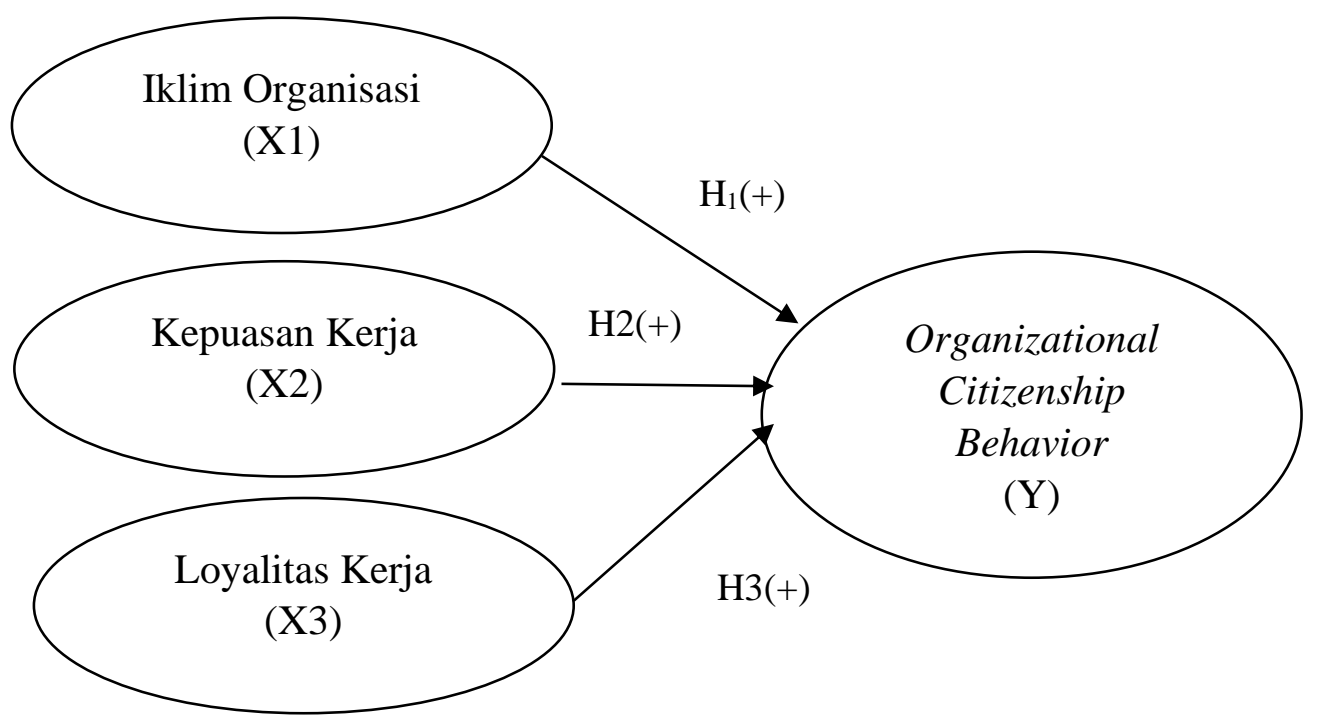

Gambar 1. Kerangka Penelitian 


\section{METODE PENELITIAN}

Penelitian ini termasuk dalam kategori penelitian asosiatif. Penelitian ini dilakukan pada Jimbaran Bay Seafood (JBS) Café Kedonganan. yang berlokasi di jalan pantai Kedonganan, Kuta, Badung, Bali. Jimbaran Bay Seafood (JBS) Cafe merupakan usaha yang bergerak di bidang kuliner yaitu seafood yang saat ini sangat diminati oleh para wisatawan yang berkunjung ke bali. Penelitian ini dilakukan karena belum banyak penelitian yang dilakukan di lokasi tersebut dan memiliki indikasi permasalahan perihal organizational citizenship behavior (OCB).

Obyek penelitian ini adalah organizational citizenship behavior (OCB) yang dippengaruhi oleh iklim organisasi, kepuasan kerja, dan loyalitas kerja. Subjek penelitian ini adalah karyawan JBS Café Kedonganan. Variabel dependen dalam penelitian ini yaitu Organizational Citizenship Behavior (OCB) yang dapat disimbolkan dengan Y. Variabel independen dalam penelitian ini adalah iklim organisasi, kepuasan kerja dan loyalitas kerja yang dapat disimbolkan dengan $\mathrm{X}_{1}$, $\mathrm{X}_{2}$, dan $\mathrm{X}_{3}$

Organizational Citizenship Behavior (OCB) dalam penelitian ini adalah perilaku seorang karyawan secara sukarela tanpa imbalan apapun untuk melakukan pekerjaan di luar tugas formalnya sehingga dapat memberikan manfaat bagi perusahaan dengan lima dimensi pada Organizational Citizenship Behavior (OCB) yaitu : Altruism (Perilaku Menolong) ( $\left.\mathrm{Y}_{1}\right)$, Conscientiousness (Kesungguhan dalam Bekerja) ( $\left.\mathrm{Y}_{2}\right)$, Courtesy (Bersikap Sopan) ( $\left.\mathrm{Y}_{3}\right)$, Sportsmanship (Toleransi yang

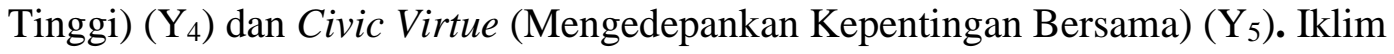
organisasi dalam penelitian ini adalah suatu situasi yang membedakan lingkungan kerja organisasi satu dengan organisasi lain yang dapat berpengaruh terhadap perilaku seorang karyawan di organisasi tersebut untuk tetap rela tinggal di dalam organisasi dengan enam indikator pada iklim organisasi yaitu : Struktur (Structure)

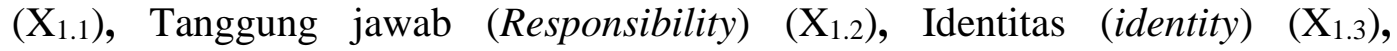
Penghargaan (Reward) $\left(\mathrm{X}_{1.4}\right)$, Dukungan (Support) $\left(\mathrm{X}_{1.5}\right)$ dan Komitmen $\left(\mathrm{X}_{1.6}\right)$

Kepuasan kerja dalam penelitian ini adalah suatu perasaan karyawan dalam menyelesaikan pekerjaan dengan ditunjukkannya sikap positif dengan indikator terjadinya suatu kepuasan kerja yaitu : Pekerjaan itu sendiri $\left(\mathrm{X}_{2.1}\right)$, Gaji $\left(\mathrm{X}_{2.2}\right)$, Kesempatan promosi ( $\left.\mathrm{X}_{2.3}\right)$, Pengawasan (Supervisi) $\left(\mathrm{X}_{2.4}\right)$, Rekan kerja $\left(\mathrm{X}_{2.5}\right)$ Loyalitas kerja dalam penelitian ini adalah kesetiaan dan usaha maksimal dari karyawan yang akan dapat menimbulkan rasa tanggung jawab dalam bekerja di suatu perusahaan. Indrawan, (2018) indikator loyalitas kerja terdiri dari beberapa unsur, yaitu : Ketaatan/Kepatuhan $\left(X_{3.1}\right)$, Kemauan untuk bekerja sama. $\left(X_{3.2}\right)$, Tanggung Jawab. $\left(\mathrm{X}_{3.3}\right)$, Pengabdian $\left(\mathrm{X}_{3.4}\right)$, Kejujuran $\left(\mathrm{X}_{3.5}\right)$

Data kuantitatif dalam penelitian ini berupa jumlah hasil kuesioner responden terhadap pernyataan yang meliputi variabel iklim organisasi, kepuasan kerja, dan loyalitas kerja serta organizational citizenship behavior (OCB). Data yang digunakan dalam penelitian ini adalah sejarah singkat organisasi dan struktur. Sumber primer pada penelitian ini adalah jawaban responden atas pernyataan yang diajukan dalam kuesioner seperti data iklim organisasi, kepuasan kerja, dan loyalitas kerja serta organizational citizenship behavior (OCB) dari perusahaan.

Sumber sekunder pada penelitian ini adalah data perusahaan berupa laporan yang telah dibuat perusahaan seperti jumlah karyawan dan gambaran umum 
organisasi. Populasi penelitian ini adalah seluruh karyawan pada Jimbaran Bay Seafood (JBS) Café Kedonganan yang berjumlah sebanyak 58 orang. Teknik pengambilan sampel dilakukan dengan sensus. Untuk memperoleh data, penelitian menggunakan teknik pengumpulan data dengan menggunakan metode observasi, kuisioner, dan wawancara.

\section{HASIL DAN PEMBAHASAN}

Awal perkembangan café ikan bakar di kawasan teluk Kedonganan dimulai pada tahun 1997 tumbuhlah beberapa café ikan bakar yang berawal dari ujung selatan pantai Kedonganan. Awalnya hanya kurang lebih 3 café ikan bakar tumbuh dan berkembang. Perkembangan inilah yang membuat penduduk Kedonganan berlomba-lomba untuk membangun café-café yang lainnya sehingga perkembangan café-café di Kedonganan berjumlah kurang lebih 80 café, menjamurnya café-café di Kedonganan yang terlalu banyak akan membawa ke persaingan yang tidak sehat dan ditambah lagi dengan semakin semrawutnya kondisi café-café tersebut. Melihat hal tersebut maka Bendesa Adat Kedonganan beserta prajuru desa adat dibawahnya berencana untuk menata café-café yang tumbuh liar tersebut menjadi café-café yang tertata dengan baik.

Dengan perjuanagan yang begitu gigih dari pak Jero Bendesa dan jajarannya maka pada tahun 2007 berhasillah mencapai kesepakatan dengan pemilik café-café lama. Maka sejak tahun 2007 di bangunlah café-café Kedonganan dengan jumlah hanya 24 café yang semuanya berbasis bisnis kemasyarakatan. Karena berbasis bisnis kemasyarakatan maka semua café di Kedonganan diatur oleh desa adat dan diserahkan kembali ke masyarakat Kedonganan melalui banjar-banjar yang ada di Kedonganan. Karena jumlah café ada 24 maka dibagi 6 banjar maka masing-masing banjar mendapat jatah 4 café.

Berdasarkan sejarah tersebut di atas maka terbentuklah kelompok café ini dinamakan Jimbaran Bay Seafood Café (JBS). Jimbaran Bay Seafood Café (JBS) didirikan pada tanggal 24 Mei 2007 dengan durasi kontrak dengan desa adat Kedonganan selama 5 tahun. Jadi setiap 5 tahun setiap café di pantai Kedonganan termasuk Jimbaran Bay Seafood Café (JBS) akan membayar iuran sejumlah tertentu yang diatur oleh desa adat. Saat ini Jimbaran Bay Seafood Café (JBS) sudah berumur 12 tahun. Perkembangan dan pertumbuhan Jimbaran Bay Seafood Café (JBS) sangatlah pesat. Tamu-tamu dari berbagai Negara, dan tamu-tamu lokal baik dari kalangan masyarakat biasa sampai artis dan pejabat tinggi negara pernah makan di Jimbaran Bay Seafood Café (JBS) sehingga sisa hasil usaha (SHU) yang didapat sangatlah bisa membuat masyarakat cukup sejahtera khususnya pemilik Jimbaran Bay Seafood Café (JBS).

Karyawan dengan jenis kelamin laki-laki berjumlah 32 orang atau sebesar 55,2 persen. Karyawan perempuan berjumlah 26 orang atau sebesar 44,8 persen. Dari data tersebut menunjukkan bahwa jumlah karyawan laki-laki lebih banyak dibandingkan dengan perempuan. Hal ini dikarenakan perusahaan lebih banyak membutuhkan karyawan laki-laki untuk menempati posisi bar, butcher, dan service/ waiters. 
Tabel 1.

Karakteristik Responden

\begin{tabular}{ccccc}
\hline No & & Klasifikasi & Jumlah \\
& & Orang & Persentase (\%) \\
\hline 1 & \multirow{2}{*}{ Jenis Kelamin } & Laki-Laki & 32 & 55,2 \\
2 & & Perempuan & 26 & 44,8 \\
& & & $\mathbf{5 8}$ & $\mathbf{1 0 0}$ \\
1 & Jumlah & SMP & 10 & 17,2 \\
2 & & SMA/SMK & 40 & 69,0 \\
3 & Pendidikan & Diploma & 7 & 12,1 \\
4 & & S1 & 1 & 1,7 \\
& & & $\mathbf{5 8}$ & $\mathbf{1 0 0}$ \\
1 & Jumlah & 1-5 Tahun & 38 & 65,5 \\
2 & & 6-10 Tahun & 11 & 19,0 \\
3 & Masa Kerja & 11-15 Tahun & 9 & 15,5 \\
& & & $\mathbf{5 8}$ & $\mathbf{1 0 0}$ \\
1 & Jumlah & 18-27 Tahun & 27 & 46,6 \\
2 & & $28-37$ Tahun & 16 & 27,6 \\
3 & & 38-47 Tahun & 10 & 17,2 \\
4 & Umur & $48-57$ Tahun & 4 & 6,9 \\
5 & & $58-67$ Tahun & 1 & 1,7 \\
& & & $\mathbf{5 8}$ & $\mathbf{1 0 0}$ \\
\hline
\end{tabular}

Sumber : Data Primer Diolah, 2019

Jumlah tertinggi terletak pada tingkat pendidikan terakhir SMA/SMK sebanyak 40 orang atau sebesar 69,0 persen. Tingkat pendidikan SMP sebanyak 10 orang atau sebesar 17,2 persen. Pada tingkat pendidikan diploma terdapat 7 orang dengan persentase sebesar 12,1 persen dan tingkat pendidikan S1 sebanyak 1 orang atau sebesar 1,7 persen. Hal ini menunjukkan bahwa Jimbaran Bay Seafood Café (JBS) Kedonganan tidak mengutamakan skill, pendidikan, dan keahlian namun lebih mengutamakan kemauan untuk bekerja.

Sebagian besar responden pada penelitian ini memiliki masa kerja antara 1 sampai 5 tahun, yaitu sebanyak 38 orang atau sebesar 65,5 persen. Karyawan dengan masa kerja 6 sampai 10 tahun sebanyak 11 orang atau sebesar 19,0 persen dan responden dengan masa kerja 11-15 tahun sebanyak 9 orang atau sebesar 15,5 persen. Hal ini menunjukkan bahwa karyawan Jimbaran Bay Seafood Café (JBS) Kedonganan di dominasi dengan karyawan yang memiliki masa kerja 1 sampai 5 tahun artinya karyawan menunjukkan tingkat loyalitas cukup baik yang disebabkan berbagai faktor seperti kesejahteraan karyawan, rasa nyaman dan pekerjaan yang disenangi oleh karyawan.

Sebagain besar responden pada penelitian ini berusia 18 sampai 27 tahun, yaitu sebanyak 27 orang atau sebesar 46,6 persen. Karyawan kelompok usia terendah yaitu pada usia 56 sampai 67 tahun dengan persentasi 1,7 persen. Hal ini menunjukkan bahwa karyawan Jimbaran Bay Seafood Café (JBS) Kedonganan didominasi karyawan berusia produktif antara 18 sampai 27 tahun, di mana pada Jimbaran Bay Seafood Café (JBS) Kedonganan memiliki sistem kerja dua shift 
yaitu pagi dan sore hari sehingga menyebabkan membutuhkan karyawan yang produktif dan kreatif dalam bekerja

Tabel 2.

Hasil Uji Validitas

\begin{tabular}{|c|c|c|c|c|}
\hline No & Variabel & $\begin{array}{c}\text { Item } \\
\text { Pernyataan } \\
\end{array}$ & $\begin{array}{c}\text { Korelasi Item } \\
\text { Total } \\
\end{array}$ & Keterangan \\
\hline \multirow[t]{6}{*}{1} & \multirow[t]{6}{*}{ Iklim Organisasi (X1) } & $\mathrm{X} 1.1$ & 0,856 & Valid \\
\hline & & $\mathrm{X} 1.2$ & 0,688 & Valid \\
\hline & & $\mathrm{X} 1.3$ & 0,818 & Valid \\
\hline & & $\mathrm{X} 1.4$ & 0,713 & Valid \\
\hline & & $\mathrm{X} 1.5$ & 0,852 & Valid \\
\hline & & $\mathrm{X} 1.6$ & 0,805 & Valid \\
\hline \multirow[t]{5}{*}{2} & \multirow[t]{5}{*}{ Kepuasan Kerja (X2) } & $\mathrm{X} 2.1$ & 0,810 & Valid \\
\hline & & $\mathrm{X} 2.2$ & 0,907 & Valid \\
\hline & & $\mathrm{X} 2.3$ & 0,890 & Valid \\
\hline & & $\mathrm{X} 2.4$ & 0,938 & Valid \\
\hline & & $X 2.5$ & 0,870 & Valid \\
\hline \multirow[t]{5}{*}{3} & \multirow[t]{5}{*}{ Loyalitas Kerja (X3) } & X3.1 & 0,869 & Valid \\
\hline & & $\mathrm{X} 3.2$ & 0,862 & Valid \\
\hline & & $\mathrm{X} 3.3$ & 0,833 & Valid \\
\hline & & X3.4 & 0,831 & Valid \\
\hline & & $\mathrm{X} 3.5$ & 0,918 & Valid \\
\hline \multirow[t]{5}{*}{4} & \multirow{5}{*}{$\begin{array}{l}\text { Organizational Citizenship } \\
\text { Behavior }(\mathrm{OCB})(\mathrm{Y})\end{array}$} & Y1.1 & 0,924 & Valid \\
\hline & & Y1.2 & 0,923 & Valid \\
\hline & & Y1.3 & 0,969 & Valid \\
\hline & & Y1.4 & 0,865 & Valid \\
\hline & & Y1.5 & 0,858 & Valid \\
\hline
\end{tabular}

Sumber : Data Primer Diolah, 2019

Tabel 3.

Hasil Uji Reliabilitas

\begin{tabular}{clcc}
\hline No & \multicolumn{1}{c}{ Variabel } & Cronbach's Aplha & Keterangan \\
\hline 1 & Iklim Organisasi (X1) & 0,876 & Reliabel \\
2 & Kepuasan Kerja (X2) & 0,925 & Reliabel \\
3 & Loyalitas Kerja (X3) & 0,911 & Reliabel \\
4 & Organizational Citizenship Behavior (OCB) (Y) & 0,936 & Reliabel \\
\hline
\end{tabular}

Sumber : Data Primer Diolah, 2019

Hasil uji validitas menunjukkan bahwa seluruh variabel memiliki nilai koefisien dengan skor total seluruh item pernyataan lebih besar dari 0,30. Hal ini menunjukkan bahwa butir-butir pernyataan sisanya dalam instrumen penelitian tersebut valid. Hasil uji reliabilitas menunjukkan bahwa instrumen penelitian yaitu 
iklim organisasi, kepuasan kerja, loyalitas kerja dan organizational citizenship behavior (OCB) memiliki koefisien Cronbach's Alpha lebih dari 0,60. Hal ini dapat dikatakan bahwa semua instrumen reliabel sehingga dapat digunakan untuk melakukan penelitian.

Jawaban responden pada variabel iklim dikategorikan sangat kondusif dengan rata-rata 4,24. Jika dilihat secara keseluruhan yaitu 2 indikator berada di bawah rata-rata variabel dan 4 indikator berada di atas rata-rata variabel. Indikator yang berada di atas rata-rata adalah indikator $\mathrm{X}_{1.1}$ sebesar 4,43 , indikator $\mathrm{X}_{1.2}$ sebesar 4,26, indikator $X_{1.3}$ sebesar 4,34, dan indikator $X_{1.5}$ sebesar 4,29. Jawaban responden pada variabel kepuasan kerja dikategorikan puas dengan rata-rata 4,10. Jika dilihat secara keseluruhan yaitu 3 indikator berada di bawah rata-rata variabel dan 2 indikator berada di atas rata-rata variabel. Indikator yang berada di atas ratarata adalah indikator $X_{1.1}$ sebesar 4,34, dan indikator $X_{1.5}$ sebesar 4,24. Jawaban responden pada variabel loyalitas kerja dikategorikan loyal dengan rata-rata 4,24.

Jika dilihat secara keseluruhan yaitu 1 indikator berada di bawah rata-rata variabel, 2 indikator berada di atas rata-rata variabel dan 2 indikator berada sama dengan rata-rata variabel. Indikator yang berada di atas rata-rata adalah indikator $\mathrm{X}_{1.1}$ sebesar 4,28, dan indikator $\mathrm{X}_{1.2}$ sebesar 4,16. Jawaban responden pada variabel organizational citizenship behaviour dikategorikan tinggi dengan rata-rata 3,90. Jika dilihat secara keseluruhan yaitu 1 indikator berada di bawah rata-rata variabel dan 4 indikator berada di atas rata-rata variabel. Indikator yang berada di atas ratarata adalah indikator $X_{1.1}$ sebesar 4,05, indikator $X_{1.2}$ sebesar 3,98, indikator $X_{1.3}$ sebesar 4,12, dan indikator $\mathrm{X}_{1.4}$ sebesar 4,17.

Tabel 4.

Hasil Analisis Regresi Linier Berganda

\begin{tabular}{lrrrrr}
\hline Model & $\begin{array}{c}\text { Unstandardized } \\
\text { Coefficients (Beta) }\end{array}$ & $\begin{array}{c}\text { Standardized } \\
\text { Coefficients } \\
\text { (Beta) }\end{array}$ & \multicolumn{1}{c}{ T } & Signifikansi \\
\hline 1 & (Constant) & $-1,528$ & & $-3,332$ &, 002 \\
& Iklim Org. &, 521 &, 343 & 3,169 &, 003 \\
Kepuasan &, 340 &, 287 & 3,793 &, 007 \\
Loyalitas &, 442 &, 352 & 3,748 &, 000 \\
R & & & & 0,861 \\
R Square & & & & 0,741 \\
F Statistik & & & & 51,456 \\
Signifikansi & & & & 0,000 \\
\hline Sumber : Data Primer Diolah, 2019 &
\end{tabular}

Berdasarkan hasil analisis regresi linier berganda maka Persamaan strukturalnya adalah sebagai berikut:

$\mathrm{Y}=0,521 \mathrm{X} 1+0,340 \mathrm{X} 2+0,442 \mathrm{X} 3$

$\mathrm{X}_{1}=0,521$, artinya iklim organisasi memiliki pengaruh positif terhadap organizational citizenship behavior (OCB) pada Jimbaran Bay Seafood Café (JBS) 
Kedonganan. $X_{2}=0,340$, artinya kepuasan kerja memiliki pengaruh positif terhadap organizational citizenship behavior (OCB) pada Jimbaran Bay Seafood Café (JBS) Kedonganan. $\mathrm{X}_{3}=0,442$, artinya loyalitas kerja memiliki pengaruh positif terhadap organizational citizenship behavior (OCB) pada Jimbaran Bay Seafood Café (JBS) Kedonganan. Nilai determinasi total sebesar 0,741 mempunyai arti bahwa sebesar 74,1 persen variasi organizational citizenship behavior dipengaruhi oleh variasi iklim organisasi, kepuasan kerja, dan loyalitas kerja sedangkan 25,9 persen dijelaskan oleh faktor lain yang tidak dimasukkan ke dalam model.

Tabel 5.

Hasil Uji Normalitas

\begin{tabular}{cc}
\hline & Unstandardized Residual \\
\hline $\mathrm{N}$ & 58 \\
Kolmogorov-Smirnov $Z$ & 0,651 \\
Asymp.Sig.(2-tailed) & 0,790 \\
\hline
\end{tabular}

Sumber : Data Primer Diolah, 2019

Nilai Kolmogorov-Smirnov $Z$ (K-S) sebesar 0,651, Besarnya nilai Asymp.Sig.(2-tailed) adalah sebesar 0,790. Hasil tersebut menunjukkan bahwa model persamaan regresi tersebut dapat berdistribusi secara normal karena nilai Asymp.Sig.(2-tailed) lebih besar dibandikan dengan nilai alpha 0,05.

Tabel 6.

Hasil Uji Multikolinearitas

\begin{tabular}{ccc}
\hline Variabel & Tolerance & VIF \\
\hline Iklim Organisasi & 0,411 & 2,435 \\
Kepuasan Kerja & 0,456 & 2,194 \\
Loyalitas Kerja & 0,544 & 1,837 \\
\hline
\end{tabular}

Sumber : Data Primer Diolah, 2019

Tabel 7.

Hasil Uji Heteroskedastisitas

\begin{tabular}{lll}
\hline & Model & Signifikansi \\
\hline 1 & (Constant) &, 000 \\
& Iklim Org &, 462 \\
& Kepuasan &, 425 \\
& Loyalitas &, 309 \\
\hline
\end{tabular}

Sumber : Data Primer Diolah, 2019

Nilai tolerance dan VIF dari seluruh variabel menunjukkan bahwa nilai tolerance untuk setiap variabel bebas lebih besar dari 0,10 dan nilai VIF lebih kecil dari 10 berarti model persamaan regresi bebas dari multikolinearitas. Nilai sig. dari regresi iklim organisasi sebesar 0,462, kepuasan kerja sebesar 0,425, dan loyalitas kerja sebesar 0,309. Nilai tersebut lebih besar dari 0,05 yang berarti masing-masing 
variabel tidak terdapat pengaruh antara variabel bebas terhadap absolute residual. Dengan demikian, model yang dibuat tidak mengandung gejala heterokedastisitas. Besarnya $\mathrm{F}$ hitung $=51,456$. Nilai $\mathrm{F}$ hitung $>\mathrm{F}$ tabel, 51,456 $>$ 2,77. Maka $\mathrm{H}_{0}$ ditolak ( $\mathrm{H}_{1}$ diterima). Kesimpulannya, iklim organisasi, kepuasan kerja, dan loyalitas kerja, secara simultan berpengaruh signifikan terhadap organizational citizenship behavior (OCB).

Berdasarkan hasil analisis pengaruh iklim organisasi terhadap organizational citizenship behavior diperoleh nilai sig. t sebesar 0,003 dengan nilai koefisien beta 0,521. Nilai Sig.t $0,003<0,05$ mengindikasikan bahwa $\mathrm{H}_{0}$ ditolak dan $\mathrm{H}_{1}$ diterima. Hasil ini mempunyai arti bahwa iklim organisasi berpengaruh positif dan signifikan terhadap organizational citizenship behavior. Berdasarkan hasil analisis pengaruh kepuasan kerja terhadap organizational citizenship behavior diperoleh nilai Sig. $\mathrm{t}$ sebesar 0,007 dengan nilai koefisien beta 0,340.

Nilai Sig. t 0,007 <0,05 mengindikasikan bahwa $\mathrm{H}_{0}$ ditolak dan $\mathrm{H}_{1}$ diterima. Hasil ini mepunyai arti bahwa kepuasan kerja berpengaruh positif dan signifikan terhadap organizational citizenship behavior. Berdasarkan hasil analisis pengaruh loyalitas kerja terhadap organizationali diperoleh nilai Sig. t sebesar 0,000 dengan nilai koefisien beta 0,442 . Nilai Sig. t $0,000<0,05$ mengindikasikan bahwa $\mathrm{H}_{0}$ ditolak dan $\mathrm{H}_{1}$ diterima. Hasil ini mempunyai arti bahwa loyalitas kerja berpengaruh positif dan signifikan terhadap organizational citizenship behavior citizenship behavior.

Hasil pengujian hipotesis variabel iklim organisasi terhadap organizational citizenship behavior pada Jimbaran Bay Seafood Café (JBS) Kedonganan memperoleh hasil yang signifikan. Hal ini diperoleh nilai Sig. t sebesar 0,003 dengan nilai koefisien beta 0,521. Tingkat signifikansi $0,003<0,05$ mengindikasikan bahwa iklim organisasi berpengaruh positif dan signifikan terhadap organizational citizenship behavior. Artinya apabila iklim organisasi meningkat maka organizational citizenship behavior karyawan akan meningkat. Berdasarkan hal tersebut maka hipotesis iklim organisasi berpengaruh positif terhadap organizational citizenship behavior dapat diterima.

Hasil penelitian tersebut mengindikasikan bahwa iklim kerja yang nyaman akan dapat menjadikan karyawan mampu meningkatkan organizational citizenship behavior. Apabila perilaku organizational citizenship behavior sudah meningkat maka akan ditandai dengan meningkatnya perilaku karyawan untuk membantu rekan kerja secara sukarela, patuh pada peraturan, tidak memberikan informasi yang dapat membuat suasana kerja karyawan lain menjadi tidak nyaman, karyawan akan mau membantu memberikan solusi apabila terjadi masalah yang sedang dihadapi sesama rekan kerja serta karyawan akan saling mendukung satu sama lain.

Pengujian hipotesis ini mengembangkan penelitian sebelumnya yang dilakukan oleh Fanis et al. (2018) yang menyatakan iklim organisasi memiliki pengaruh positif terhadap organizational citizenship behavior. Hasil penelitian Lubis (2015) menunjukkan bahwa iklim organisasi memiliki pengaruh positif dan signifikan terhadap organizational citizenship behavior. Penelitian Rinenthis (2018) menjelaskan bahwa iklim organisasi mempunyai pengaruh yang signifikan terhadap OCB. Ukkas \& Latif (2017) menyatakan bahwa adanya pengaruh positif dan signifikan iklim organisasi terhadap organizational citizenship behavior. 
Suifan (2016) menyatakan bahwa terdapat hubungan yang sangat signifikan antara iklim organisasi dan organizational citizenship behavior dengan arah positif bahwa semakin tinggi atau baik maka iklim organisasi akan meningkatkan organizational citizenship behavior. Hasil penelitian Shahin et al. (2015) menegaskan iklim organisasi menunjukkan gaya hidup orang dari sebuah organisasi, dengan menciptakan iklim organisasi yang kondusif akan menghasilkan organizational citizenship behavior.

Hasil pengujian hipotesis variabel kepuasan kerja terhadap organizational citizenship behavior pada Jimbaran Bay Seafood Café (JBS) Kedonganan diperoleh nilai Sig. t sebesar 0,007 dengan nilai koefisien beta 0,340. Tingkat signifikansi $0,007<0,05$ mengindikasikan bahwa kepuasan kerja berpengaruh positif dan signifikan terhadap organizational citizenship behavior. Artinya apabila kepuasan kerja meningkat maka organizational citizenship behavior karyawan akan meningkat. Berdasarkan hal tersebut maka hipotesis kepuasan kerja berpengaruh positif terhadap organizational citizenship behavior dapat diterima.

Hasil penelitian ini mengindikasikan bahwa para karyawan akan mendapatkan kepuasan kerja, sehingga akan memunculkan kerelaan karyawan untuk melakukan pekerjaan di luar deskripsi pekerjaannya. Peningkatan organizational citizenship behavior pada karyawan dapat dilakukan dengan cara meningkatkan kepuasan mereka. Adanya kesesuaian antara gaji yang diberikan perusahaan dengan beban kerja yang diterima akan dapat meningkatkan kepuasan kerja karyawan. Selain itu, apabila karyawan merasa puas dengan pekerjaannya maka karyawan akan bekerja dengan penuh tanggung jawab. Karyawan akan puas dengan pekerjaannya, apabila karyawan diberlakukan dengan baik oleh sesama rekan kerja dan juga atasan. Serta karyawan akan puas, jika dalam bekerja karyawan akan diberikan kesempatan promosi.

Pengujian hipotesis ini mengembangkan penelitian yang dilakukan oleh Penelitian Soegandhi et al. (2013) menyatakan bahwa kepuasan kerja berpengaruh positif dan signifikan terhadap Organizational Citizenship Behavior karyawan PT. Surya Timur Sakti Jatim. Kepuasan kerja berpengaruh positif dan signifikan terhadap Organizational Citizenship Behavior (OCB). Semakin tinggi kepuasan kerja karyawan maka akan semakin meningkat Organizational Citizenship Behavior (OCB) (Nurhayati et al., 2016)

Laksana \& Surya (2018) menyatakan bahwa kepuasan secara positif dan signifikan berpengaruh terhadap Organizational Citizenship Behavior (OCB). Hal ini menunjukkan semakin tinggi kepuasan kerja yang dimiliki oleh guru maka semakin tinggi pula tingkat OCB yang dimiliki guru SMAN 1 Blahbatuh. Wahyuni \& Supartha (2019), keadilan organisasional, komitmen organisasional dan kepuasan kerja berpengaruh positif dan signifikan terhadap Organizational Citizenship Behavior (OCB). Dalam penelitian Mahardika \& Wibawa (2019) dinyatakan bahwa kepuasan kerja berpengaruh positif dan signifikan terhadap organizational citizenship behavior terhadap karyawan Focus Design Artglass Ubud.

Hasil pengujian hipotesis variabel loyalitas kerja terhadap organizational citizenship behavior pada Jimbaran Bay Seafood Café (JBS) Kedonganan diperoleh nilai Sig. t sebesar 0,000 dengan nilai koefisien beta 0,442. Tingkat signifikansi 
$0,000<0,05$ mengindikasikan bahwa loyalitas kerja berpengaruh positif dan signifikan terhadap organizational citizenship behavior. Artinya apabila loyalitas kerja karyawan meningkat maka organizational citizenship behavior karyawan akan meningkat. Berdasarkan hal tersebut maka hipotesis loyalitas kerja berpengaruh positif terhadap organizational citizenship behavior dapat diterima.

Hasil penelitian ini mengindikasikan bahwa apabila karyawan loyal terhadap pekerjaannya maka akan dapat menimbulkan perilaku organizational citizenship behavior. Perilaku organizational citizenship behavior yang meningkat dapat ditandai dengan meningkatnya kepatuhan karyawan pada peraturan di perusahaan, karyawan mau bekerja sama, karyawan merasa memiliki tanggung jawab pada pekerjaan yang diberikan, karyawan merasa bahwa dirinya perlu memberikan sumbangan pikiran dan tenaganya secara iklas, serta karyawan akan jujur pada perusahaan. Perilaku organizational citizenship behavior para karyawan dapat ditingkatkan dengan cara meningkatkan rasa loyalitas karyawan terhadap perusahaan.

Pengujian hipotesis ini mengembangkan penelitian sebelumnya yang dilakukan oleh Prameswari \& Suwandana (2017) menyatakan perilaku organisasi menciptakan suatu iklim yang menunjang dalam loyalitas karyawan contohnya yaitu lamanya bekerja karyawan ditunjukkan dengan rendahnya tingkat turnover. Loyalitas kerja berpengaruh positif terhadap Organizational Citizenship Behavior karyawan PT Surya Timur Sakti Jatim oleh Soegandhi et al. (2013). Rusdi \& Chan (2015), kepuasan Kerja dan Loyalitas Kerja berpengaruh terhadap Organizational Citizenship Behavior (OCB). Namun, Nurhayati et al. (2016) menyatakan loyalitas kerja berpengaruh positif dan signifikan terhadap Organizational Citizenship Behavior (OCB). Artinya semakin tinggi loyalitas kerja karyawan maka akan semakin meningkat Organizational Citizenship Behavior (OCB).

Penelitian ini telah mampu menjelaskan model teori tentang nilai-nilai yang terkandung dalam iklim organisasi, kepuasan kerja, dan loyalitas kerja dalam mempengaruhi organizational citizenship behaviour (OCB). Hasil model teoritis menjelaskan bahwa nilai-nilai yang terkandung dalam iklim organisasi, kepuasan kerja, dan loyalitas kerja secara langsung mempengaruhi organizational citizenship behaviour (OCB). Penelitian ini menegaskan konsep iklim organisasi, kepuasan kerja, dan loyalitas kerja berpengaruh positif terhadap organizational citizenship behaviour (OCB). Hasil penelitian ini mengungkapkan pentingnya pihak manajemen dalam memperhatikan seberapa besar iklim organisasi, kepuasan kerja, dan loyalitas kerja dalam mempengaruhi tingkat organizational citizenship behaviour (OCB).

Hasil Penelitian ini memberikan implikasi praktis kepada pihak manajemen Jimbaran Bay Seafood Café (JBS) Kedonganan di mana berdasarkan penilaian tertinggi yang ada pada indikator "struktur" variabel iklim organisasi menunjukkan bahwa apabila perusahaan memiliki struktur yang jelas, maka dapat mempengaruhi organizational citizenship behaviour di dalam JBS café. Penilaian tertinggi pada indikator "pekerjaan itu sendiri" variabel kepuasan kerja menunjukkan bahwa apabila karyawan puas dengan pekerjaan yang dilakukan, maka dapat mempengaruhi organizational citizenship behaviour diperusahaan. Pekerjaan yang menyenangkan akan menyebabkan karyawan puas dengan perusahaannya, 
sehingga dapat menyebabkan karyawan bekerja dengan sepenuh hati. Penilaian tertinggi pada indikator "ketaatan/kepatuhan" variabel loyalitas kerja menunjukkan bahwa apabila karyawan loyal kepada pekerjaan, maka dapat mempengaruhi organizational citizenship behaviour.

\section{SIMPULAN}

Iklim organisasi berpengaruh positif dan signifikan terhadap organizational citizenship behavior (OCB) pada Jimbaran Bay Seafood Café (JBS) Kedonganan. Hal ini menunjukkan apabila iklim organisasi meningkat, maka organizational citizenship behavior karyawan akan meningkat. Kepuasan kerja berpengaruh positif dan signifikan terhadap organizational citizenship behavior (OCB) pada Jimbaran Bay Seafood Café (JBS) Kedonganan. Hal ini menunjukkan apabila kepuasan kerja meningkat maka organizational citizenship behavior karyawan akan meningkat.. Loyalitas kerja berpengaruh positif dan signifikan terhadap organizational citizenship behavior (OCB) pada Jimbaran Bay Seafood Café (JBS) Kedonganan. Hal ini menunjukkan apabila loyalitas kerja karyawan meningkat maka organizational citizenship behavior karyawan akan meningkat.

Pihak perusahaan menjaga dan memperhatikan indikator penghargaan (Reward) yang merupakan indikator dari iklim organisasi yang berkaitan dengan meningkakan kepedulian atasan dalam menghargai pekerjaan yang sudah dilakukan karyawannya dengan cara memberikan dorongan terhadap apa yang perlu dilakukan. Gaji merupakan indikator dari kepuasan kerja yang berkaitan dengan pernyataan bahwa mengerjakan beban kerja yang terlalu besar dibandingkan dengan gaji yang didapat karyawan dapat dilakukan dengan cara memberikan kesempatan kepada karyawan untuk dapat menyampaikan pendapatnya tentang beban kerja yang dihadapi agar pekerjaan yang dilakukan dapat seimbang dengan gaji yang diterima. Indikator pengabdian yang merupakan indikator dari loyalitas kerja berkaitan dengan pernyataan menyampaikan ide dengan sesama rekan kerja, dapat dilakukan dengan cara meningkatkan komunikasi dengan sesama rekan kerja agar adanya masukan dalam melaksanakan pekerjaan. Apabila perusahaan dapat meningkatkannya maka karyawan akan mampu meningkatkan organizational citizenship behavior di Jimbaran Bay Seafood Café (JBS) Kedonganan.

Bagi peneliti selanjutnya diharapkan dapat menambah beberapa variabel yang berbeda yang memiliki hubungan dengan iklim organisasi, kepuasan kerja, loyalitas kerja dan organizational citizenship behaviour agar hasil penelitian dapat bervariasi dan dapat memperkaya referensi yang ada. Selain itu, melihat keterbatasan yang ditemukan pada penelitian ini, peneliti selanjutnya juga diharapkan untuk memperluas ruang lingkup wilayah penelitian dan lokasi penelitian sehingga hasil penelitian dapat diimplementasikan secara umum.

\section{REFERENSI}

Berberoglu, A. (2018). Impact of organizational climate on organizational commitment and perceived organizational performance: empirical evidence from public hospitals. BMC Health Services Research, 18(399), 1-10. 
Campbell, K. M. (2015). Flexible Work Schedules, Virtual Work Programs, and Employee Productivity. Journal of Walden Dissertations and Doctoral Studies, 19(7), 172-194.

Devi, D. A. W. S., \& Adnyani, I. G. A. D. (2015). Pengaruh Kepuasan Kerja Karyawan Terhadap Komitmen Organisasional Dan Organizational Citizenship Behaviour (OCB) Pada PT. Maharani Prema Sakti Denpasar. EJurnal Manajemen Universitas Udayana, 4(12), 4105-4134.

Fanis, A. T., \& Rahmi, F. (2016). Pengaruh Iklim Organisasi terhadap Organizational Citizenship Behavior pada Karyawan Bank X. Jurnal Riset Aktual, 7(1), 1-10. https://doi.org/https://doi.org/10.24036/rapun.v7i1.6602

Fanis, A. T., Rahmi, F., \& Andalas, U. (2018). Pengaruh iklim organisasi terhadap organizational citizenship behavior pada karyawan bank $x$. Universitas Muhammadiyah Malang.

Fitriani, N. W., \& Dewi, I. G. A. M. (2017). Pengaruh Iklim Organisasi dan Loyalitas Kerja Terhadap Organizational Citizenship Behavior. E-Jurnal Manajemen Universitas Udayana, 6(5), 2501-2527.

Gunduz, Y. (2014). The Effect of Organizational Support on Organizational Commitment. Anthropologist, 18(3), 1041-1057.

Harper, P. J. (2015). Exploring forms of organizational citizenship behaviors ( OCB ): antecedents and outcomes. Journal of Management and Marketing Research, 18(2), 1-16.

Khan, S. A., Ali, M., Hussain, H. F., \& Safdar, B. S. (2015). Impact of Employee Training and Motivation on Business Development in Banking Sector : Study Conducted in Pakistan. American Journall of Business, Economics and Management, 3(5), 241-249.

Laksana, D. M. A. P., \& Surya, I. B. K. (2018). Pengaruh Kepemimpinan Transformasional Dan Kepuasan Kerja Terhadap OCB Pada Guru Sma Negeri 1 Blahbatuh. E-Jurnal Manajemen Universitas Udayana, 7(2), 584-613.

Lubis, M. S. (2015). Pengaruh Iklim Organisasi Dan Komitmen Organisasi Terhadap Pembentukan Organizational Citizenship Behavior (Ocb) Karyawan Dalam Rangka Peningkatan Kinerja. E-Jurnal Apresiasi Ekonomi, 3(2), 7584.

Mahardika, I. N. B. P., \& Wibawa, I. M. A. (2019). Pengaruh Budaya Organisasi Kepuasan Kerja dan Komitmen Organisasional Terhadap Organizational Citizenship Behavior Pada Karyawan. E-Jurnal Manajemen Universitas Udayana, 8(1), 7340-7370.

Mahendra, I. M. D., \& Surya, I. B. K. (2017). Pengaruh Iklim Organisasi, Motivasi Kerja, Dan Keadilan Organisasi Terhadap Organizational Citizenship Behavior (OCB). E-Jurnal Manajemen Universitas Udayana, 6(9), 46594688 . 
Masoud, P., Abdolmajid, F., \& Farhad, G. (2014). Explaining The Relationship Between Organizational Climate, Organizational Commitment and Organizational Citizenship Behavior Among Emppployees of Khuzestan Gas Company. Indian Journal of Fundamental and Applied Life Sciences, 4(3), 282-290.

Mighfar, S. (2015). Social Exchange Theory. Jurnal Lisan Al-Hal, 9(2), 261-286.

Ningtias, P. A., \& Sunuharyo, B. S. (2018). Pengaruh Iklim Organisasi Dan Organizational Citizenship Behavior Terhadap Kinerja Karyawan. Jurnal Administrasi Bisnis (JAB), 64(1), 19-27.

Nurhayati, D., Minarsih, M. M., \& Wulan, H. S. (2016). Pengaruh kepuasan kerja dan Loyalitas Kerja Terhadap Organizational Citizenship Behavior ( OCB ) ( Studi Kasus Pada PT . Perwirabhakti Sentrasejahtera Di Kota Semarang ). Jurnal Of Management, 2(2), 12-24.

Pitaloka, E., \& Sofia, I. P. (2015). The Affect of Work Environment, Job Satisfaction, Organizational Commitment on OCB of Internal Auditors. International Journal of Business Economics and Law, 5(2), 10-18.

Pozveh, A. Z., \& Karimi, F. (2017). The relationship between organizational climate and organizational citizenship behaviors of the staff members in the Department of Education in Isfahan city. International Journal of Educational and Psychological Research, 3(1), 53-60.

Prameswari, N. K. S., \& Suwandana, I. G. M. (2017). Pengaruh Keadilan Organisasional, Komitmen Organisasional, Dan Kepuasan Kerja Terhadap Organizational Citizenship Behavior. E-Jurnal Manajemen Universitas Udayana, 6(3), 1368-1397.

Puangyoykeaw, K., \& Nishide, Y. (2015). Organizational Commitment and Turnover Intention in Low-Skilled Immigrant Workers in Thailand: An Empirical Assessment of Need Satisfaction, Job Satisfaction and Overall Life Satisfaction Factors. International Journal of Business and Management, 10(5), 98-112.

Putrana, Y., Fathoni, A., \& Warso, M. M. (2016). Pengaruh Kepuasan Kerja dan Komitmen Organisasi Terhadap Organizational Citizenship Behavior Dalam Meningkatkan Kinerja Karyawan PT. Gelora Persada Mediatama Semarang. Journal Of Management, 2(2), 1-14.

Rauf, F. H. A. (2014). Perception of Organizational Justice as a Predictor of Organizational Citizenship Behavior: An Empirical Study at Schools in Sri Lanka. European Journal of Business and Management, 6(12), 124-131.

RINENTHIS, P. D. (2018). Organizational Citizenship Behaviour Sebagai Variabel Dari Iklim Organisasi Dan Leader's Personality Traits Pada Kinerja Karyawan Pt Suara Merdeka Press Kantor Perwakilan Kota Surakarta (Institut Agama Islam Negeri 
https://doi.org/10.1017/CBO9781107415324.004

Rusdi, M. Y., \& Chan, S. (2015). Pengaruh Kepuasan Kerja dan Loyalitas Karyawan Terhadap Organizational Citizenship Behavior Serta Dampaknya Pada Efektifitas Perusahaan PT. Markplus Inc. Jurnal Manajemen Pascasarjana Universitas Syiah Kuala, 4(2), 149-159.

Shahin, A., Naftchali, S. J., \& Pool, K. J. (2015). Developing a model for the influence of perceived organizational climate on organizational citizenship behaviour and organizational performance based on balanced score card. International Journal of Productivity and Performance Management, 63(3), 290-307.

Sharma, A. (2016). Managing diversity and equality in the workplace. Cogent Business \& Management, $3(1), \quad 1-20$. https://doi.org/https://doi.org/10.1080/23311975.2016.1212682

Soegandhi, V. M., Sutanto, E. M., \& Setiawan, R. (2013). Pengaruh Kepuasan Kerja dan Loyalitas Kerja Terhadap Organizational Citizenship Behavior Pada Karyawan PT Surya Timur Sakti Jatim. Jurnal AGORA, 1(1), 2-12.

Subramani, A. K., Jan, N. A., Gaur, M., \& Vinodh, N. (2015). Impact of organizational climate on organizational citizenship behaviour with respect to automotive industries at Ambattur industrial estate, Chennai. I $J A B E R$, 13(8), 97-107.

Suifan, T. S. (2016). The Impact of Organizational Climate and Psychological Capital on Organizational Citizenship Behavior. International Journal of Business and Management, 11(1), 224-230.

Sukarman, Said, S., Hamzah, N., \& Ella, H. (2018). Role of work motivation and organizational culture in improving the performance of civil servants and organizational citizenship behavior (OCB) in Boalemo District Gorontalo Province. International Journal of Scientific and Technology Research, 7(11), 44-51.

Sunarta. (2019). Pentingnya Kepuasan Kerja. Jurnal Efisiensi, XVI(2), 63-75.

Ukkas, I., \& Latif, D. (2017). Pengaruh Iklim Organisasi Dan Komitmen Organisasi Terhadap Organizational Citizenship Behavior (OCB). Jurnal Ilmiah Ekonomi, Manajemen Dan Akuntansi, 6(1), 19-28.

Wahyuni, N. P. D. E., \& Supartha, I. W. G. (2019). Pengaruh Keadilan Organisasional, Komitmen Organisasional, dan Kepuasan Kerja Terhadap Organizational Citizenship Behavior (OCB). E-Jurnal Manajemen Universitas Udayana, 8(9), 6079-6098.

Yanti, P. E. T., \& Supartha, I. W. G. (2017). Pengaruh Komitmen Organisasional dan Kepuasan Kerja Terhadap Organizational Citizenship Behavior (OCB). EJurnal Manajemen Universitas Udayana, 6(2), 721-747. 
Kadek Nabella Sri Astarini, Iklim Organisasi, Kepuasan...

Yu, C., Sun, H., \& Han, B. (2015). Design and implementation of Chinese high star-level hotel management information system. International Conference on Education Technology, 1(7), 234-237.

Zayas-ortiz, M., Rosario, E., Marquez, E., \& Gruñeiro, P. C. (2015). Relationship between organizational commitments and organizational citizenship behaviour in a sample of private banking employees. International Journal of Sociology and Social Policy, 35(1), 91-106. 